\title{
Arquitetura infantil: como a arquitetura pode ser uma influenciadora no aprendizado das crianças e não as deixar crescerem com dificuldade no aprendizado
}

No Brasil há várias discussões sobre a qualidade e o desempenho das escolas. $\mathrm{O}$ ambiente escolar deve abrigar as crianças para que elas fiquem mais confortáveis. Está em discussão também o modelo ideal para o índice de aprendizado aumentar, fazendo com que se consiga melhorar a integração dos espaços sem ficar preso a estética. O principal objetivo é compreender como que a arquitetura e a educação têm a capacidade de caminharem juntas e fazer do ambiente escolar e o ensino melhores, analisando a importância de cada ambiente e suas funções, optando por espaços mais coloridos e mais humanizados.

Palavras-chave: Arquitetura infantil; Aprendizado; Humanização; Integração.

\section{Children's architecture: how architecture can influence children's learning and not let them grow up with learning difficulties}

In Brazil, there are several discussions about the quality and performance of schools. The school environment should shelter children so that they are more comfortable. Also under discussion is the ideal model for the learning index to increase, making it possible to improve the integration of spaces without being tied to aesthetics. The main objective is to understand how architecture and education have the ability to walk together and make the school environment and teaching better, analyzing the importance of each environment and its functions, opting for more colorful and more humanized spaces.

Keywords: Children's architecture; Learning; Humanization; Integration.

\section{Topic: Arquitetura e Urbanismo}

Reviewed anonymously in the process of blind peer.
Received: 09/10/2019

Approved: 19/01/2020
Camilo Geraldo Garcia Prado

Universidade de Franca, Brasil

http://lattes.cnpq.br/1774542616489985

camiloggprado59@gmail.com

Talita Silva Castro

Universidade de Franca, Brasil

talita2013castro@gmail.com do

DOI: 10.6008/CBPC2674-6395.2020.001.0002
Referencing this:

PRADO, C. G. G.; CASTRO, T. S.. Arquitetura infantil: como a arquitetura pode ser uma influenciadora no aprendizado das crianças e não as deixar crescerem com dificuldade no aprendizado. Inventionis, v.2, n.1, p.15-22, 2020. DOI: http://doi.org/10.6008/CBPC2674-6395.2020.001.0002 
Arquitetura infantil: como a arquitetura pode ser uma influenciadora no aprendizado das crianças e não as deixar crescerem com dificuldade no aprendizado

\section{INTRODUÇÃO}

É muito discutido pelo Brasil o modelo ideal de sala de aula para melhorar a qualidade de ensino. A arquitetura vem tomando espaço cada vez mais para melhorar a qualidade dos ambientes e da vida das pessoas. A escola não seria um lugar diferente. Arquitetos e educadores devem pensar bem nos projetos escolares, devendo haver projetos específicos para cada comunidade, fazendo com que os alunos se interessem mais pela escola, principalmente a criança até cinco anos que são as mais difíceis de ganhar a confiança quando o assunto é escola.

Devem-se proporcionar espaços mais humanizados e integrando o interno com o externo, criando uma harmonia de cores, com espaços amplos, conforto através da ventilação e iluminação natural, conforto acústico, móveis planejados e personalizados pelos alunos e paredes táteis que ajudem no desenvolvimento intelectual e na coordenação motora. Kowaltowski (2011) cita 32 parâmetros arquitetônicos para melhorar e aumentar qualidade da educação no Brasil. O tema arquitetura infantil surge da dificuldade que os jovens têm no aprendizado e nada melhor do que começar a tratar essa deficiência de aprendizado na infância.

\section{DISCUSSÃO TEÒRICA}

\section{Arquitetura x Educação}

A educação vem gerando muitas discussões pelo Brasil. A qualidade é muito questionada, principalmente nas avaliações de desempenho que são feitas pelos alunos das escolas públicas. A escola tem o papel de dar a oportunidade de uma educação como prioridade preparando os alunos para uma sociedade mais justa e humana.

Vem gerando discussões também o modelo ideal de sala e sobre como deve ser o ambiente de aprendizado. A escola não deve somente abrigar os alunos, ela deve ser integrada com a metodologia de ensino e a arquitetura escolar, proporcionando um espaço de troca de informações e de interatividade entre alunos e professores.

O espaço escolar é o local de desenvolvimento do aprendizado e o edifício deve ser o resultado da cultura social e espelhar os aspectos que vão além da sua materialização, sendo assim o modelo de escola ideal não tem um parâmetro só, mas se resume na ordem arquitetônica, pedagógica e social.

Ceppi et al. (2013) dizem que o espaço de convivência deve ser integrado, mas sem ficar preso na estética do ambiente. Sendo assim pesquisando muito sobre o assunto e de como utilizar os espaços, mas ao mesmo tempo de como manter a conexão entre eles, resultando em ambientes mais agradáveis e produtivos para as crianças.

Um ambiente caracterizado pelas relações que consegue estimular ou possibilitar um espaço relacional, cuja qualidade não deriva de uma teoria, mas de uma maneira de enxergar, ler, estudar, interpretar a realidade e de representá-la com consciência crítica. (CEPPI et al., 2013)

Não há necessidade de a escola ser dividida em grupos, mas sim se deve haver a característica local no ambiente. É interessante que vários marcos e pontos da cidade sejam espelhados no ambiente escolar 
Arquitetura infantil: como a arquitetura pode ser uma influenciadora no aprendizado das crianças e não as deixar crescerem com dificuldade no aprendizado

PRADO, C. G. G.; CASTRO, T. S.

fazendo assim que as crianças se sintam parte do pequeno espaço da educação. A igualdade de cidade e escola não deve ser só de horários ou atividades, mas também de características de espaço fazendo assim que torne um espaço híbrido.

Segundo Kowaltowski (2011) as mais simples modificações são as melhores para resolver os problemas para deixar os alunos mais confortáveis. O modelo de sala de aula do futuro é discutido para se tornarem mais amplas, mas mantendo o formato tradicional, somente variando a disposição dos móveis e com inclusão de equipamentos digitais. $\mathrm{O}$ ambiente escolar tem o modelo de salas fechadas, cheias de carteiras enfileiradas e voltada para a lousa e um professor à frente, trazendo desmotivação para os alunos.

O início de um projeto escolar tem que surgir com a necessidade e o proposto de criar espaços para facilitar o aprendizado e se adequar ao conteúdo. Em seu livro Kowaltowski (2011) tem como exemplo 32 parâmetros baseados em Nair e Fielding.

\section{Parâmetros de projeto:}

\section{Sala de aulas, ambiente de ensino e comunidade pequenas de aprendizado}

Registra a avaliação do ambiente adequado relacionando com os aspectos físicos do ambiente escolar e da filosofia de ensino. Gil (2002) diz que as escolas devem oferecer e possibilitar mais variedades no ambiente escolar. Deve-se criar espaços diversificados que incluem vários grupos de trabalhos.

\section{Entrada convidativa}

A entrada da escola deve despertar, convidar e chamar a atenção dos alunos para que se sintam seguros ao entrar no ambiente escolar. O projeto deve separar a escola da sociedade, ter cobertura para acolher os alunos na entrada e saída, tendo como integração a administração e área comunitária, contendo na área de entrada painéis para expor os trabalhos.

\section{Espaços de exposição dos trabalhos}

Este parâmetro prevê espaços para a exposição de trabalhos dos alunos que deve ser feito em áreas coletivas como entrada, corredores e até mesmo a sala de aula. Tendo como meio de exposição os quadros, os pôsteres, os desenhos, as maquetes, objetos tridimensionais e equipamentos por todo prédio escolar.

\section{Espaços individuais para armazenamento de materiais}

Os armários não são hábitos brasileiros, mas deveríamos reservar espaços para guardar os materiais mais usados, sendo dispostos próximos à sala de aula ou a uma área de estudo para evitarmos que os alunos carregam peso. É viável também que cada aluno tenha uma mesa fixa para poder personalizar.

\section{Laboratório de ciências e artes}

Na escola é preciso ter um espaço de aprendizado prático, para aplicar os conceitos ensinados. Os 
Arquitetura infantil: como a arquitetura pode ser uma influenciadora no aprendizado das crianças e não as deixar crescerem com dificuldade no aprendizado

PRADO, C. G. G.; CASTRO, T. S.

ambientes podem ser em laboratórios, com móveis flexíveis, área de exposição dos trabalhos, área para trabalhos feitos com água e tinta que seriam feitos em um espaço de integração interno e externo.

\section{Arte, música e atuação}

Esse parâmetro tem o intuito de investigar e inserir os alunos em atividades artísticas no ambiente escolar e participar. Os ambientes devem ser amplos para a exposição de obras de arte, lugares para apresentação de teatro e um espaço que seja multiuso que possa funcionar para um público grande.

\section{Área de educação física}

A atividade física sustentável aumenta o desempenho, a saúde mental e o bem-estar dos alunos, mas essa questão poderia ser melhorada se tivesse atividades nos espaços internos como caminhada, natação recreativa e treinamento com pesos.

\section{Áreas casuais de alimentação}

Faltam elementos estéticos para deixar o espaço mais agradável e atraente, para melhorar esse ambiente, algumas medidas como deixar os horários mais flexíveis para lanches, as refeições serem em lugares menores, sem ser no grande refeitório, móveis mais confortáveis e descontraídos, deixar os alunos personalizarem o ambiente do jeito deles e deixar esses espaços mais abertos para depois serem usados como café.

\section{Transparência}

Esse parâmetro tem como importância a integração do interno com o externo, criando sensação de liberdade nos ambientes, mas sem interferir na acústica, deixando a área administrativa mais aberta, para monitorar os alunos mais facilmente, ter corredores com mais luz natural, vista para o externo evitando sensação de estarem presos.

\section{Vista interiores e exteriores}

Os alunos passam o dia todo em salas de aula, por isso deveriam ser oferecidos estudos com vista para ambientes externos tornando as aulas mais aconchegantes por conta da vista. Há discussões que está vista atrapalha o rendimento em sala de aula tirando a concentração, mas estudos comprovam que a falta de interesse pelo conteúdo depende do que está acontecendo dentro de sala de aula, não por causa do que acontece do lado externo.

\section{Tecnologia distribuída}

A tecnologia é muito importante no ambiente escolar para a comunicação, descobrir o mundo, jogar, buscar e colaborar com os estudos, por isso deveria ter salas especificas para esse uso em todas as escolas. 
Arquitetura infantil: como a arquitetura pode ser uma influenciadora no aprendizado das crianças e não as deixar crescerem com dificuldade no

\section{Conexão entre espaço externo e interno}

As crianças têm necessidade de sentir a natureza, por isso o ambiente escolar deve oferecer essa integração e proporcionar o uso para fazer trilhas, circuitos, hortas, salas ao ar livre, espaço para ler, sentar e descobrir tudo conectando o interno e o externo.

\section{Mobiliário macio para sentar}

Os alunos reclamam muito que as cadeiras são duras e como os alunos passam muito tempo sentados, a ergonomia e maciez das cadeiras devem ser priorizadas, colocando estofados e tendo mais variedade de móveis para sentar, melhorando a postura e o rendimento.

\section{Espaços flexíveis}

Deveríamos optar por espaços flexíveis dando vários usos para um único espaço. São indicados módulos de estrutura inteligentes para que possa ser feito a vedação dos espaços mais simples e rápidos, disporem a infraestrutura seguindo a modulação e proporcionando de vários jeitos, colocarem divisórias acústicas, elementos estruturais para fechamento de ambientes e cálculo reforçado de laje.

\section{Campfire}

É usado em contador de histórias para compartilhar conhecimento e despertar o interesse por discussões. O ambiente seria como em um teatro, tendo um tablado paro o contador ficar, com aparelhos eletrônicos, acústica boa para melhor propagação do som, cortinas para bloqueio de luz que seja de fácil manuseio.

\section{Watering hole space}

É um ambiente informal para ajudar desenvolver as habilidades no aprendizado dos alunos. É uma miniárea que parece uma cozinham com vista para o externo e são especificas para atividades em grupo.

\section{Cave space}

É um espaço usado para reflexão e estudo muitas vezes confundido com a biblioteca, mas é um espaço que não exige silencio absoluto e pode ser usado como área externa.

\section{Projeto para inteligências múltiplas}

Cada aluno tem facilidade com uma atividade seja linguística, musica, arte, dança, exercício corporal, interação social e individual, devendo ser parte da escola investigar esses dons em cada aluno, fazendo um ambiente especifico para essas atividades. 
Arquitetura infantil: como a arquitetura pode ser uma influenciadora no aprendizado das crianças e não as deixar crescerem com dificuldade no aprendizado

\section{Iluminação natural}

É importante saber interagir o interno com o externo mantendo uma boa iluminação natural que é fundamental para o bem-estar fisiológico e psicológico apoiando eficiência energética do edifício.

\section{Ventilação natural}

A ventilação aumenta a qualidade do ar deixando mais puro e evitando fungos e mofos nestes ambientes. É importante a ventilação natural para manter o bem-estar e assim aumentando a produção dos alunos em relação a suas atividades.

\section{Iluminação, cor e aprendizado}

A iluminação e a cor devem estar combinando com a atividade proposta em cada ambiente, as cores também devem estar compatíveis com a iluminação para oferecer mais conforto aos olhos dos alunos.

\section{Elementos de sustentabilidade}

Em escolas de alto padrão a palavra sustentabilidade é uma das palavras mais usadas quando dá início a um projeto. Para diminuir o impacto deveria usar recursos da terra, utilizar materiais recicláveis para diminuir a emissão de gases tóxicos e reaproveitar a água da chuva.

\section{Assinatura local}

O projeto escolar deve expressar a metodologia proposta e também os valores da comunidade local. A qualidade é importante e um elemento para destacar a instituição.

\section{Conexão com a comunidade}

A escola deve estar conectada com a comunidade sendo construída ao centro do bairro, ter relação com a sociedade local e poder usar a escola para eventos comunitários.

\section{O pátio, a implantação da escola e adequação dos espaços livres}

O ambiente que tem as suas próprias funções juntamente com a quadra suprira a necessidade de haver um pátio, sendo que muitas vezes o pátio acaba virando refeitório para uso de danças, músicas e outras apresentações e acaba não tendo a sua função que é somente abrigar as pessoas.

\section{Incorporação na quadra de esportes no volume da edificação}

A quadra dever ser localizada em uma área onde pode ser facilmente observada. O medo é quando é situada em local perto de sala de aula por conta do barulho que as crianças fazem ao realizar as atividades. 
Arquitetura infantil: como a arquitetura pode ser uma influenciadora no aprendizado das crianças e não as deixar crescerem com dificuldade no aprendizado

\section{Fechamento de área}

É importante para segurança do patrimônio e das pessoas que ali estão que a escola seja fechada, mas deve ser pensada para não se tornar feia ou parecendo uma prisão, sendo assim pode-se optar por muros vazados ou vegetações que formem desenhos criativos.

\section{Integração externa entre os espaços}

Vários volumes são implantados no terreno e muitas vezes o nível é diferente entre o prédio dificultando a circulação, para facilitar é indicado utilizar passarela como elemento marcante e ser coberto por causa da chuva.

\section{Dimensionamento de aspectos funcionais}

Na maioria dos parâmetros a funcionalidade foi bastante discutida, mas no Brasil não há estudos sobre isso. A escola tem como base a área útil por aluno e o espaço é considerado essencial.

\section{Conforto acústico}

No Brasil a acústica é pouco usada, mas seria ideal se as escolas fossem espelhadas nas escolas internacionais levando para a sala de aula acústica no teto, nas paredes e pisos que sejam antialérgicos e de fácil limpeza.

\section{Acessibilidade}

A acessibilidade é um desenho universal fundamental para vivencia do indivíduo no ambiente, impedindo à separação de pessoas por meio dos elementos arquitetônicos que dão diferentes acessos as pessoas com equipamentos de circulação.

\section{Síntese dos parâmetros}

O ideal seria melhorar a qualidade do ambiente escolar, desenvolvendo propósito pedagógico vinculado com as necessidades atuais e futuras da sociedade. O INEP/MEC tem estudos que apontam que 13\% da população diz que escolas públicas são ruins e isso atrapalha o aprendizado.

Kowaltowski (2011) diz que existe um padrão que deve ser seguido e que ninguém teve a preocupação de fazer um ambiente de acordo com a comunidade. A questão política muitas vezes atrapalha para as escolas serem única, os políticos barram a secretaria de educação, não deixando contratar profissionais competentes para fazer um projeto especifico para comunidade.

\section{CONCLUSÕES}

O estudo expõe o principal problema dos motivos da qualidade do ensino nas escolas brasileiras ser tão baixa. Fica claro que o espaço mal elaborado desmotiva os alunos a estarem naquele espaço fazendo 
com que o rendimento escolar caia cada vez mais. A proposta do trabalho (ou da pesquisa) é mostrar a importância de ambientes humanizados e integrados, mais abertos, com atividades diversas para criar um maior interesse dos alunos pela escola.

Por fim Kowaltowski (2011) mostra 32 parâmetros para projetar uma escola do zero a tornando-a melhor e mais convidativa para os alunos, definir uma melhor linguagem gráfica do projeto de ambientes educacionais mais saudáveis e mais funcionais.

\section{REFERÊNCIAS}

GIL, A. C.. Como elaborar projeto de pesquisa. 4 ed. São Paulo: Atlas, 2002.

CEPPI, G.; ZINI, M.. Crianças, espaços, relações como projetar ambientes para a educação infantil. Porto Alegre:
Penso, 2013.

KOWALTOWSKI, D.C. C. K. Arquitetura escolar: o projeto do ambiente de ensino. São Paulo: Oficina de textos, 2011.

A CBPC - Companhia Brasileira de Produção Científica (CNPJ: 11.221.422/0001-03) detém os direitos materiais desta publicação. Os direitos referem-se à publicação do trabalho em qualquer parte do mundo, incluindo os direitos às renovações, expansões e disseminações da contribuição, bem como outros direitos subsidiários. Todos os trabalhos publicados eletronicamente poderão posteriormente ser publicados em coletâneas impressas sob coordenação da Cognitionis Publishing, da Companhia Brasileira de Produção Científica e seus parceiros autorizados. Os (as) autores (as) preservam os direitos autorais, mas não têm permissão para a publicação da contribuição em outro meio, impresso ou digital, em português ou em tradução. 